\title{
田
}

\section{O COOPERATIVISMO NO MOVIMENTO DOS TRABALHADORES RURAIS SEM TERRA}

The cooperativism in the landless rural workers movement

\section{Caio Martins ${ }^{1}$}

\section{RESUMO}

Este artigo tem como objetivo analisar a função do cooperativismo no MST como parte da estratégia de sua luta anticapitalista. Para isso, em primeiro lugar, abordamos brevemente os limites ontológicos do cooperativismo, enquanto práxis de sentido emancipatório, quando mediada pela produção social global capitalista. A partir da análise dos processos de trabalho neste modo de produção, na esteira da teoria marxista, destacamos como uma característica ineliminável e constitutiva a subsunção do trabalho concreto ao trabalho abstrato. Tal fator torna impossível a plena autonomia dos trabalhadores sobre seu próprio trabalho e, portanto, sua emancipação. Considerando tais limites, reconhecidos pelo próprio MST, questionamos sua presença marcante no movimento, buscando contextualizar o cooperativismo na sua estratégia de luta. Para isso, em um segundo momento, descrevemos breve e historicamente o período em que o MST surge, as condições objetivas das quais parte e sobre as quais age, para articulá-las com sua estratégia de luta. A partir dessa historicização, argumentamos que a razão de ser do cooperativismo no MST

\footnotetext{
${ }^{1}$ Graduação e Mestrado em Administração pela Universidade Federal de Santa Catarina, Aluno do Programa de Pós-graduação em Serviço Social da Universidade Federal do Rio de Janeiro. Email: <caiomarti@yahoo.com.br>.
} 
é fundamentalmente pedagógica e política. Trata-se de manter nos assentamentos, como acontece nos acampamentos, os trabalhadores organizados e em luta mesmo após a conquista da propriedade da terra. A formação de assentamentos coletivos, com a constituição de cooperativas de trabalho, é um meio para conciliar a permanência no campo com os princípios político-ideológicos do MST, favorecendo a educação de quadros para as suas lutas permanentes.

\section{PALAVRAS-CHAVE}

Cooperativismo. MST. Capitalismo.

\section{ABSTRACT}

This article aims to analyze the role of cooperatives in the MST as part of its strategy to anti-capitalist strugle. For this, first we briefly addressed the ontological limits to cooperatives, whilst practice for emancipation, when mediated by the global social capitalist production. From the analysis of the work processes in this mode of production, based on the Marxist theory, the subsumption of the concrete work to the abstract work stands out as a constituent and ineliminable characteristic. This factor makes it impossible for workers to achieve full autonomy over their own work and hence their emancipation. Considering these limitations, acknowledged by the MST, we question its strong presence in the movement, seeking to contextualize the cooperative in their struggle strategy. For this, in a second moment, we make a brief and historical description of the period in which the MST appears, the objective conditions of which they appear and on which they act, to link them with their struggle strategy. We argue, from this historicization, that the purpose of the cooperatives in MST is mainly pedagogical and political. This is to keep in the settlements, as it happens in the encampments, the workers organized and in control even after the conquest of land ownership. The formation of collective settlements, with the formation of work cooperatives is a way to conciliate the permanence in the rural fields with the political and ideological principles of 
the MST, favoring the education of men and women for their permanent struggles.

\section{KEYWORDS}

Cooperativism. MST. Capitalism.

\section{INTRODUÇÃO}

O capital, cujo movimento ontologicamente incontrolável subordina a si todas as áreas de atividade humana, "[...] desde os processos econômicos básicos até os domínios intelectuais e culturais mais sofisticados" (MÉSZÁROS, 2004, p. 16), é um sistema sociometabólico dotado de lógica própria. Tal sistema possui leis que lhe são imanentes e que se impõem a qualquer movimento particular de nossa sociedade como condições objetivas, com as quais tem de se defrontar qualquer movimento que vise à sua superação.

As leis do modo de produção capitalista constituem um complexo alienante que reifica as relações entre seres humanos e fetichiza suas objetivações. Têm, por conta disso, efeitos desumanizantes tanto no espaço da circulação da riqueza socialmente produzida que corresponde à sua distribuição e à decisão sobre o quê se quer produzir, à natureza da produção e do consumo etc. - quanto nas relações de produção em si. Estas, por sua vez, abrangem as técnicas de produção, relações de dominação nas organizações produtivas (que refletem em outros espaços da vida social), na divisão hierárquica do trabalho, na sua intensificação e perda de sentido etc.

Como resposta a esses efeitos desumanizantes, surgem ao longo da história do capitalismo diversos movimentos contestatórios, entre os quais os chamados movimentos cooperativistas, que se inserem tanto na esfera da produção como na da circulação. Tais movimentos possuem claros limites emancipatórios, como atesta toda a crítica desenvolvida pela tradição marxista. Especialmente no que se refere às chamadas fábricas-cooperativas (esfera da produção), essa tradição demonstra o caráter híbrido dessas organizações que, ao mesmo tempo em que emancipa politicamente os 
trabalhadores na gestão dos processos de trabalho, constrange-os a realizá-la subsumida a critérios especificamente capitalistas.

No entanto, há movimentos sociais de grande importância para as aspirações emancipatórias na América Latina - como o Movimento dos Trabalhadores Rurais Sem Terra (MST) - que retomam, na prática, essa questão. Esse resgate por parte dos movimentos sociais é o que nos leva a tratar da função estratégica, no contexto de mundialização do capital monopolista, da bandeira do cooperativismo içada pelo MST.

É nesse sentido que problematizamos a questão do cooperativismo no Movimento dos Trabalhadores Rurais Sem Terra sob um ponto de vista emancipatório, comunista. Para isso, retomamos, em primeiro lugar, os limites ontológicos do cooperativismo, enquanto práxis emancipatória, quando mediada pela produção social global capitalista. Em um segundo momento, situamos o cooperativismo na luta do MST, procurando articular as condições objetivas com as quais se defronta o movimento com sua estratégia e, assim, evidenciar a função do cooperativismo nesse contexto.

\section{OS LIMITES ONTOLÓGICOS DO COOPERATIVISMO NO CAPITALISMO}

As cooperativas são uma forma particular de organizar o trabalho para, no capitalismo, produzir mercadorias. É muito comum compreendermos o trabalho como sinônimo de emprego, como um meio de vida. A categoria trabalho, contudo, existe independente das relações assalariadas; é elemento ontológico do ser social e fundante de toda a sociabilidade. Assim, para a satisfação de nossas necessidades, toda sociedade produz relações que interagem organicamente com a natureza e esta interação, sempre orientada a um fim, constitui o trabalho (MARX, 1988).

Trata-se, portanto, de uma atividade orientada a um fim pré-concebido, de um processo teleológico (LUKÁCS, 1969, p. 6). No ato do trabalho, o ser humano antecipa idealmente em sua cabeça seu objetivo e o modo pelo qual pretende realizá-lo para satisfazer suas necessidades. "O trabalho é formado por posições teleológicas que, em cada oportunidade, põem em funcionamento séries cau- 
sais". A causalidade representa a lei espontânea com a qual tem de interagir necessariamente o trabalho; a teleologia, por sua vez, “[...] é um modo de pôr - posição sempre realizada por uma consciência - que, embora guiando-as em determinada direção, pode movimentar apenas séries causais".

O trabalho aparece, assim, como categoria mediadora entre sujeito e objeto, constituindo-se, pois, como base ontológica de toda práxis humana. Esta, por sua vez, em relação a qual o trabalho é um elemento particular - e fundamental -, aparece como categoria universal mediadora entre sujeito e objeto. Ou seja, toda práxis é uma mediação entre sujeito e objeto. E, uma vez que nem toda práxis interage organicamente com a natureza para a satisfação de necessidades humanas, nem toda práxis é trabalho. Qualquer práxis, por outro lado, tornar-se-ia impossível sem a existência do trabalho - práxis particular que permite a existência e reprodução da sociabilidade humana (TONET, 1995).

Podemos observar, portanto, que os processos de trabalho são sempre constituídos por uma prévia-ideação e uma objetivação. Assim, todo ser que trabalha não o faz sem antes planejar sua ação, mesmo que de um modo muito rudimentar. Tal planejamento (a prévia-ideação) leva sempre em conta o contexto historicamente determinado com o qual se defronta o sujeito que trabalha.

Por essa razão, o caráter teleológico do trabalho tem características específicas nas sociedades de classes, uma vez que os momentos da concepção e execução são separados de acordo com a formação das relações estabelecidas entre as classes dominantes e as classes subalternas. Ao longo de nossa história, ao passo que as classes dominantes exercem a atividade intelectual, as classes subalternas - as que transformam diretamente a natureza - exercem o trabaIho manual. Mas como a atividade intelectual necessita controlar as objetivações que transformam efetivamente a natureza, o trabalho intelectual das classes dominantes não é outra coisa senão o desenvolvimento e aplicação de um modo eficiente de controlar as classes subalternas de acordo com seus interesses de classe. O trabalho manual, por sua vez, não perde seu momento teleológico, mas passa agora também a considerar sua posição de classe no momento de 
sua prévia-ideação. Ou seja, a subjetividade do trabalhador manual passa a levar em conta o controle estranho ao qual está sujeito e não apenas as necessidades as quais pretende satisfazer. Ambas as atividades - a intelectual da classe dominante e a manual das classes subalternas - permanecem constituídas pelo momento da prévia-ideação seguida da objetivação, mas agora determinadas por suas posições de classe. As complexidades específicas que assumem essa relação dão forma à relação ontologicamente estabelecida entre o gênero humano e a natureza ao longo da história.

É da oposição entre o que concebe e o que executa, entre o que gere e o que é gerido, entre o que manda e o que obedece, que nasce a heterogestão e o desenvolvimento de todo um aparato técnico e teórico para controlar a força de trabalho subordinada e sujeita aos fins da classe dominante. Essa oposição se faz presente em todas as sociedades de classes, inclusive na sociedade capitalista. Nesta, como sabemos, a propriedade privada dos meios de produção funda-se como meio de apropriação de mais-valia, produzida por uma parcela imensa da sociedade de seres desprovidos da propriedade de tais meios (MARX, 1988).

Foi buscando negar tal efeito desumanizante que surgiram as cooperativas na sociedade capitalista; organizações que pretendem produzir mercadorias eliminando a presença da oposição entre concepção e execução, retomando sua unidade; que fundam sua práxis organizacional com processos autogeridos. Essas organizações - como não poderiam deixar de ser - também concebem seus processos teleologicamente, mas com base em uma forma horizontal de dividir o trabalho, o que, a princípio, eliminaria as oposições de classe e, portanto, a apropriação de mais-valia. Por outro lado, também interagem com séries causais sobre as quais não têm qualquer controle. Por isso, para compreender os limites ontológicos das cooperativas na sociedade capitalista, passaremos primeiro à apreensão das leis que regulam tais séries causais.

A interação orgânica com a natureza se objetiva, no capitalismo, grosso modo, em mercadorias. É através da compra de mercadorias, portanto, que são satisfeitas nossas necessidades: do "estômago à fantasia", como disse Marx (1988).

No intercâmbio de mercadorias, suas características concretas, sua 
finalidade etc., não determinam seu valor. Isso porque abstraímos no processo de troca as características concretas e específicas das mercadorias que têm, todavia, de ser socialmente úteis. Resta-lhes de comum que são todas frutos de um dispêndio de trabalho humano. Mas, novamente, as características concretas do trabalho, os processos do trabalho que lhes deram origem, têm de ser abstraídos também, pois somente por processos qualitativamente diferentes podem-se produzir valores de uso distintos.

Tendo desaparecido o caráter útil dos produtos do trabalho, "desaparece o caráter útil dos trabalhos neles representados e desaparecem também, portanto, as diferentes formas concretas desses trabalhos" (MARX, 1988, p. 47). Não se diferenciam mais um do outro para serem reduzidos em sua totalidade a trabalho abstrato. Portanto, o trabalho abstrato, quantificado pelo tempo socialmente necessário para a produção de determinada mercadoria, é a substância do valor das mercadorias.

Entretanto, para uma empresa particular - ou seja, do ponto de vista dos capitalistas - o valor da mercadoria aparece como algo dado pelo mercado, que foge ao seu controle, visto que ele é determinado pela totalidade de empresas que produzem uma mercadoria de determinada espécie. A empresa capitalista opera ciente da produtividade que o mercado demanda. Como o desenvolvimento das forças produtivas é também social - e como os meios de produção, as máquinas e a tecnologia tendem a estar disponíveis a todas as empresas que possam comprá-las, uma vez que são também elas mercadorias -, a empresa, para tornar-se competitiva, tem poucas alternativas. Ela tem de se adequar tecnicamente ao contexto social no qual opera e sobre o qual a lei do valor das mercadorias exerce pressão fundamental.

Não é sem razão que Marx (1988, p. 260) chama a atenção para o seguinte fato:

Que se aplique a uma mercadoria apenas o tempo de trabalho socialmente necessário à sua produção, aparece na produção mercantil em geral como compulsão externa da concorrência, porque, expresso superficialmente, cada produtor individual tem de vender sua mercadoria pelo seu preço de mercado. O fornecimento de dado quan- 
tum de produtos num tempo de trabalho determinado torna-se na manufatura lei técnica do próprio processo de produção (grifo nosso).

Ou seja, em circunstâncias históricas dadas, o tempo socialmente necessário, o qual é imbricado com o grau de desenvolvimento das forças produtivas, aparece no mercado como uma "[...] compulsão externa da concorrência [...]” (MARX, 1988, p. 260), criando, por consequência, uma "lei técnica", isto é, um modo certo de se produzir.

As cooperativas, a despeito de seu modo horizontal de dividir o trabalho, também estão sujeitas à "[...] compulsão externa da concorrência [...]” (MARX, 1988, p. 260) do mercado capitalista. Têm, portanto, de lidar com o movimento do capital cujo fim é sua constante autovalorização, subordinando a essa finalidade todos os processos organizacionais. Podemos dizer, portanto, que as séries causais com que se defrontam as empresas capitalistas e as cooperativas são frequentemente, e na essência, as mesmas. A diferença entre as empresas capitalistas e as cooperativas reside não no elemento objetivo, mas, sobretudo, no elemento subjetivo da práxis. Nas empresas capitalistas, desenvolveu-se um aparato administrativo que se opõe aos operários no tratamento da "[...] compulsão externa da concorrência [...]" (MARX, 1988, p. 260). Nas cooperativas autogeridas, são os próprios trabalhadores que têm de lidar com essas questões. Por isso, todo o processo de trabalho de qualquer organização produtora de mercadorias realiza-se nos estreitos limites do trabalho abstrato.

É por essa razão que Luxemburgo (1999, p. 80-81) considerava a cooperativa um ser híbrido dentro da economia - uma pequena produção socializada imersa em um intercâmbio social capitalista -, que terminaria por levar os operários à "[...] necessidade contraditória de governar-se a si mesmos com todo o absolutismo necessário e desempenhar entre eles mesmos o papel do patrão capitalista".

Lembremos que o capitalista é, para Marx (1988), apenas a personificação do capital. Sua posição na produção social não Ihe dá outra alternativa que não a reprodução ampliada de seu capital. A existência de ilhas de produção autogeridas cria ape- 
nas novas formas de personificação do capital. Vejamos esta passagem de Marx (1985):

Apenas na medida em que é capital personificado, tem o capitalista valor histórico e aquele direito histórico à existência [...]. Somente nessa medida sua própria necessidade transitória está embutida na necessidade transitória do modo de produção capitalista. Mas, nessa medida, também não é o valor de uso a satisfação, mas o valor de troca e sua multiplicação o móvel de sua ação. Como fanático da valorização do valor, ele força sem nenhum escrúpulo a humanidade à produção pela produção [...]. Apenas como personificação do capital, o capitalista é respeitável. Como tal, ele partilha com o entesourador o instinto absoluto do enriquecimento. O que neste, porém, aparece como mania individual, é no capitalista efeito do mecanismo social, do qual ele é apenas uma engrenagem. Além disso, o desenvolvimento da produção capitalista faz do contínuo aumento do capital investido numa empresa industrial uma necessidade e a concorrência impõe a todo capitalista as leis imanentes do modo de produção capitalista como leis coercitivas externas. Obriga-o a ampliar seu capital continuamente para conservá-lo, e ampliá-lo ele só o pode mediante acumulação progressiva (MARX, 1985, p. 172, grifo nosso).

Se é verdade que os trabalhadores das cooperativas personificam o capital e que, por essa razão, têm de tomar como suas as necessidades do capital, também o é que o contínuo aumento do capital investido torna-se uma necessidade, derivada das "leis coercitivas externas". Dessa forma, já aqui podemos observar que as cooperativas têm de manter um nível adequado em seus custos de produção. Como o capital reproduz-se ampliadamente, isto é, transformando a mais-valia apropriada em capital para aumentar a grandeza da acumulação, não restam às cooperativas outras alternativas senão a de repetir este processo por meio de uma espécie de auto-exploração do trabalho.

Temos aqui uma característica fundamental do mercado capitalista para compreender sua influência sobre as relações organizacionais. As leis coercitivas externas do capital incidem sobre as empre- 
sas como uma força estranha que impele a reprodução ampliada e que influencia, naturalmente, sua composição técnica.

Há, portanto, claras determinações do mercado sobre as tecnologias adotadas pelas cooperativas, que influenciam em grande medida, inclusive, o modo de organizar o trabalho (auto ou heterogestão). Por isso, se é verdade que o desenvolvimento histórico do modo de produção capitalista separou - e até mesmo opôs - concepção e execução na forma correspondente de administração e operacionalização, ele também criou, ao mesmo tempo, conhecimentos tecnológicos embasados e direcionados a essa separação. Desse modo, as tecnologias dos processos de trabalho podem ser divididas em tecnologias de gestão (concepção) e tecnologias físicas (execução) (FARIA, 1992).

Segundo Faria (1992), a tecnologia de gestão consiste na aplicação de conhecimentos relacionados às técnicas, instrumentos ou estratégias utilizadas pelos administradores para controlar o processo de produção em geral, de tal modo que seja capaz de otimizar os recursos nele empregados. Compreende, desse modo, tanto elementos de ordem instrumental, como a racionalização e formalização dos processos de trabalho, como de ordem comportamental e ideológica. As tecnologias físicas, por sua vez, estão relacionadas aos instrumentos de trabalho e aos métodos de sua utilização (FARIA, 1992). Ambas as categorias são os elementos constitutivos das tecnologias do processo de trabalho, e por essa razão mantêm íntima e necessária conexão. A gestão da produção, nessa perspectiva, consiste basicamente no controle desses dois elementos que constituem a tecnologia de processo, independentemente da forma específica que assuma.

O que podemos observar é que, na melhor das vezes, as cooperativas desenvolvem, nos marcos do trabalho abstrato e da reprodução capitalista, tecnologias de gestão adequadas aos seus princípios político-ideológicos. Por outro lado, tornam-se impotentes, a despeito de qualquer esforço, para transformar a tecnologia física e os critérios de distribuição da riqueza com base nos mesmos princípios que orientam a tecnologia de gestão. Ao contrário, têm de reproduzir tecnologias físicas adequadas à produção capitalista. Ou seja, a tecnologia de gestão não elimina a determinação fundamental que os leva a adotar como critério de 
decisão os imperativos sociais; a transformar em vontade do trabalhador as necessidades do capital.

Isso porque, como discorremos ao longo desse artigo, as cooperativas (como qualquer empresa) defrontam-se com séries causais na sua práxis produtiva sobre as quais não exercem qualquer controle. As leis imanentes ao modo de produção capitalista não dependem de sua vontade particular. Ao produzirem mercadorias, produzem objetos que possuem um valor determinado socialmente pelo conjunto da produção capitalista. Para tornar viável a produção cooperativa, portanto, têm de fazer frente à concorrência das demais empresas no mercado. É essa concorrência e a realização da produção através do mercado que constrangem o desenvolvimento de tecnologias físicas adequadas aos princípios socialistas do MST. Ao invés disso, a produção de mercadorias ocorre com a reprodução de tecnologias físicas desenvolvidas para fins de acumulação, de reprodução ampliada do capital. Por isso, as cooperativas não fazem mais que romper parcialmente com as relações sociais capitalistas.

No mundo tal como tem sido - e continua a ser - transformado pelo imenso poder do capital, as instituições sociais constituem um sistema estreitamente articulado. Por isso, não há quaisquer esperanças de sucessos parciais isolados, mas somente de sucessos globais, por mais paradoxal que isso possa soar. De fato, o critério crucial para a adoção de medidas parciais é se são ou não capazes de operar como [...] alavancas estratégicas para uma reestruturação radical do sistema global de controle social (MÉSZÁROS, 2009, p. 73-4).

É nesse sentido que trataremos, agora, de situar o cooperativismo, com todos esses limites, nas lutas do MST, para que possamos refletir sobre suas possibilidades objetivas de articulação de suas bandeiras históricas e sua função estratégica no movimento.

\section{O COOPERATIVISMO NO MST}

A razão de ser do MST é a luta pela reforma agrária. O movimento surge como força contestadora diante da histórica concentração de terras no Brasil, no contexto da implantação das reformas 
neoliberais na América Latina, aglutinando trabalhadores rurais que, desprovidos de uma propriedade na qual pudessem produzir para sobreviver, organizam-se na luta pela redistribuição das terras cultiváveis. Dessa forma, o MST é um movimento de trabalhadores que luta antes por meios de produção, sem o qual o trabalho não pode objetivar-se, do que por melhores condições de trabalho assalariado.

Ao longo do seu processo de construção, o MST adquiriu a visão política segundo a qual o problema da luta pela terra só se resolve através de sua socialização, o que implica necessariamente a superação da sociedade capitalista. Assim, não se trata aqui de considerar a luta imediata do MST, qual seja, a luta pela reforma agrária, como em si mesma revolucionária, mas de situá-la como mediação estratégica do horizonte socialista do movimento, considerando sua base social e suas possibilidades objetivas historicamente determinadas.

Segundo Germer (1994a, 1994b), a principal forma de trabalho no meio rural é hoje o trabalho assalariado, sejam eles assalariados puros ou híbridos, isto é, o semiproletariado, constituído por pequenos proprietários, arrendatários, que têm na atividade produtiva em suas terras apenas um complemento à atividade assalariada. No plano político-organizativo, a base sobre a qual o MST se erigiu é predominantemente o semiproletariado agrário, ou seja, os pequenos agricultores semiautônomos (semiassalariados). Paradoxalmente, os assalariados puros, apesar de sua posição estratégica, não constituem a camada mais combativa, papel o qual vem sendo exercido pelo MST, cuja principal bandeira é a reforma agrária sob o controle dos trabalhadores.

O semiproletariado é a camada constituída por antigos camponeses em vias de proletarização por conta da tendência fundamental do modo de produção capitalista de concentração de capital. É por isso que o MST é originariamente constituído por trabalhadores expulsos do campo, que querem, por meio da reforma agrária, nele permanecer. Nesse sentido, o movimento só pode afetar a produção capitalista indiretamente, isto é, no plano político e no núcleo jurídico-ideológico, quando questionam as formas burguesas de propriedade (MACHADO, 2007; MACHADO; GONÇAL- 
VES, 2007). O enfrentamento do MST não é um enfrentamento imediato ao capital, mas ao Estado que garante manutenção de seu sociometabolismo. É, portanto, essencialmente, um enfrentamento de semiassalariados organizados no MST pela propriedade de meios de produção, através da repartição da propriedade privada. O movimento adquire um caráter anticapitalista porque combate, frente ao Estado, a concentração de capital no campo ou, nos termos do MST, o agronegócio. E foi essa luta pela Reforma Agrária que transformou o movimento, o qual passou por um processo pedagógico fundamental.

Por todas essas razões é que a luta do MST é contra a burguesia agrária pela redistribuição das terras cultiváveis, que permitiriam a retomada do controle da produção pelos trabalhadores. Mas tal luta não pode se limitar a isso, como argumenta Germer (1994b), uma vez que há uma tendência inexorável em nossa sociedade de concentração de capital, o que no meio rural significa também a concentração de terras e o consequente processo de proletarização. Enquanto restrito à redistribuição de terras cultiváveis, o MST desemboca em dilemas da luta anti-sistêmica inerentes às próprias condições objetivas sobre as quais age (MACHADO, 2007).

Podemos dizer que a luta pela reforma agrária se desdobra em dois momentos distintos: o do enfrentamento ao Estado pelo processo de redistribuição da propriedade (negação), que, traduzido na prática do MST, é o momento do acampamento; e o da manutenção das conquistas realizadas, da defesa da propriedade conquistada, que constitui o processo de assentamento (positivação) (MACHADO; GONÇALVES, 2007).

O acampamento é a ocupação de latifúndios ou terras improdutivas que são reivindicadas para o processo de assentamento de famílias. É nesse momento, também, em que o questionamento do caráter de classe do Estado é, de modo mais evidente, revelado - a propriedade latifundiária é diretamente questionada e desnaturalizada pelo movimento de contestação. Lá, em meio a uma extrema tensão política, além das dificuldades econômicas por que passam os militantes, ocorre um processo político-pedagógico importante por meio da constituição do grupo e que tende a fortalecer a identidade de classe. Nesse embate, põem-se 
em xeque os valores mais tradicionais, individualistas, machistas etc., mediante um processo de formação política concomitante à luta pela conquista da terra (DALMAGRO, 2002).

Na luta pela reforma agrária, a relação entre os Sem-Terra é amplamente democrática, organizada em comissões e núcleos de base (MORISSAWA, 2001; VENDRAMINI, 2005). As decisões a respeito da estratégia do movimento são debatidas nos núcleos e deliberadas na assembleia. Ao mesmo tempo, os militantes têm de aprender a organizar a produção coletivamente nas condições mais precárias, agravadas pela repressão política de que são alvos. Por isso, afirma Vendramini (2005, p. 70) que "[...] a organização e vida num acampamento exige extrema organização, disciplina e regras muito firmes e o aprendizado de viver e organizar a vida junto com outras pessoas, dantes desconhecidas". Por outro lado, ao mesmo tempo desvelam-se nesse processo trajetórias comuns de exploração, proletarização, trabalho precário, revelando uma identidade em cada história singular antes obscurecida pelas relações sociais capitalistas.

O que parece ocorrer aqui é aquilo que lasi (2006) descreve como um salto qualitativo do indivíduo encapsulado ao grupo como uma totalidade dialética. A partir da base de uma serialidade, isto é, de um conjunto aleatório de indivíduos unidos casualmente por condições comuns, pode instituir-se uma espécie de movimento coletivo a partir do reconhecimento de seu ser no outro. Nesse processo de reconhecimento, a história individual e a negação de suas aspirações pela objetividade deixam de ser vistas como uma sina individual: não se trata mais "[...] da família que não consegue mais produzir seu sustento na terra [...]", mas "[...] do conjunto dos trabalhadores rurais sem terra que foram expulsos do campo pelo 'agronegócio' [...]”. Nesse movimento, o indivíduo cria um sentimento de pertença que faz com que o ser social subsumido pela forma individualizante se veja "[...] como parte de uma coletividade que lhe dá identidade e no interior da qual experimenta uma força que fora dela desconhecia [...]" (IASI, 2006, p. 261-262). É a ação do grupo e a emergência dessa força dantes desconhecida que possibilitará uma práxis livre, isto é, a práxis que, ao fragilizar os elementos que funcionavam como imposições restritivas internalizadas, subverte a realidade e torna 
possível o que era impossível. O grupo, ao superar o "[...] campo prático-inerte [...]”, cria o espaço da expressão livre da práxis. Nesse momento, vivencia-se um processo "[...] de negação da serialidade e da primeira forma de consciência [a individual], principalmente por propiciar que o ser humano se veja como sujeito de uma possível mudança de algum aspecto, inicialmente pontual, que vivenciou como injustiça [...]" (IASI, 2006, p. 282).

Algo semelhante ocorre nos acampamentos do MST. Essa experiência singular de vida coletiva na luta pela terra - que rompe as "[...] cápsulas individuais [...]" com o surgimento do grupo e que é orientada pela luta comum pela propriedade dos meios de produção - é elemento fundamental para a organização do futuro assentamento. A história necessariamente singular de cada grupo, na sua constituição e na metamorfose por que passa a sua subjetividade, determina o modo como serão assentadas as famílias e, por conseguinte, as relações que serão estabelecidas entre elas. Por isso, os assentamentos do MST adquirem traços particulares que, não raras vezes, os diferenciam substancialmente uns dos outros (VENDRAMINI, 2005, p. 72). No entanto, antes de qualquer diferença, possuem determinações em comum. Vejamos.

Como afirma Vendramini (2005, p. 72), “[...] a passagem para o assentamento significa uma vitória, que traz consigo muitos desafios e conflitos. No acampamento estavam mobilizados para a luta pela terra, portanto, tinham algo muito forte em comum". Uma vez assentados, passam a se deparar com um complexo de problemas qualitativamente diferentes dos tempos de luta pela terra. Trata-se agora de um processo de normalização da nova vida que tem no seu centro o trabalho como forma de defesa das conquistas alcançadas. Mas, notem bem, não qualquer trabalho, mas aquele que é subsumido ao trabalho abstrato; subsumido, portanto, socialmente ao capital. Surge uma forte tendência por conta dos imperativos do movimento do capital para que o grupo que outrora possibilitou a práxis livre não seja mais "[...] uma força que diante da impossibilidade da impossibilidade se move para a ação, mas [constitua-se], ele próprio, parte de um novo campo prático-inerte que se move pela reprodução da inércia de certas impossibilidades" (IASI, 2006, p. 293). 
Se no acampamento aflora-se a pedagogia da luta política, através do enfrentamento direto com as forças do Estado, no assentamento, por outro lado, todos os esforços são direcionados para a manutenção da propriedade conquistada (MACHADO, 2007). E, por mais que os militantes não percam a identidade de Sem Terra, mantendo os vínculos com seus pares ainda não assentados por meio dos coordenadores das brigadas e dos liberados, sua atividade prática cotidiana não é mais de contestação, mas de afirmação da propriedade da terra. Dessa forma, "[...] a prioridade conferida objetivamente à viabilidade econômica dos assentamentos contribui para que haja um refluxo das lutas [...]" em favor de objetivos mais imediatos relacionados à manutenção da terra adquirida (MACHADO; GONÇALVES, 2007, p. 16). Por essa razão, os assentamentos acabam se tornando um grande desafio ao movimento.

Aquilo que serve como motor de organização do proletariado em classe - o questionamento jurídico-político da concentração da propriedade privada dos meios de produção em pouquíssimas mãos - perde força política quando se torna assentado, pois é obrigado a produzir para o ‘mercado' e, além disso, tem que demonstrar a viabilidade econômica [...] (MACHADO, 2007, p. 178).

Insistimos: o trabalho concreto é, no capitalismo, subsumido ao trabalho abstrato. Por isso, a práxis produtiva como forma de luta anticapitalista, necessariamente mediada pela totalidade social, é fortemente limitada. E é aqui que desvelamos o papel do cooperativismo no MST: o movimento busca contrapor esta tendência de retorno à serialidade por meio da organização do assentamento em cooperativas. Pretende, assim, manter a coesão do grupo e sua movimentação política construídas durante a luta pela terra.

Toda a organização dos assentamentos do MST leva em conta a preocupação em manter a coesão do grupo. Não é por outra razão que, para manter as famílias unidas, as moradias costumam ser próximas umas das outras, formando as agrovilas ou núcleos de moradia. "Nessa estrutura, é dada primazia para a democracia direta. Em cada núcleo de base, que integra em média 15 famílias, todos, inclusive os jovens, as crianças e os idosos, discutem e decidem os destinos do assentamento em todos os assuntos" (MORISSAWA, 2001, p. 228). 
A proximidade das famílias no assentamento contribui para a formação de cooperativas. O MST tem como princípio de sua organização que "[...] a cooperação deve evoluir das formas simples para as mais complexas [...]" (MORISSAWA, 2001, p. 232). Mas, por outro lado, todas as formas de cooperação praticadas pelo movimento, independente do grau de complexidade, têm a mesma finalidade: manter a luta política no assentamento.

São as cooperativas de produção que consideramos, como Marx (1986, p. 334), “[...] dentro da antiga forma, a primeira ruptura da forma antiga, embora naturalmente, em sua organização real, por toda parte reproduzam e tenham de reproduzir todos os defeitos do sistema existente". No MST, essas cooperativas de produção são denominadas CPAs. Parece-nos, portanto, que há uma diferença fundamental entre os assentamentos de lotes individuais ou familiares, e os assentamentos com Cooperativas de Produção Agropecuária.

A socialização dos meios de produção aliada à autogestão exige que os indivíduos mantenham-se, por assim dizer, com suas cápsulas individuais rompidas. Enquanto nas demais formas de cooperação a prática da produção e tudo que ela implica é individualizada, nos assentamentos com CPAs a práxis laborativa organizada coletivamente exige permanente interação entre os Sem Terra. Essa interação permanente, por sua vez, é fonte de um rico aprendizado político e esse é seu principal papel dentro do MST.

Podemos dizer, portanto, que o processo de assentamento pode resultar em duas formas distintas: o assentamento individual e 0 assentamento coletivo. Os assentamentos individuais são aqueles em que a porção da terra dedicada ao assentamento é repartida em pequenos lotes, de propriedade particular de cada família assentada. Os assentamentos coletivos são aqueles cujos meios de produção são de propriedade do grupo e combinam as formas mais complexas de cooperação do movimento. Neles, terra, capital e trabalho são socializados e as relações democráticas entre os trabalhadores permeiam tanto a produção quanto a política do movimento. São os assentamentos coletivos que são capazes de atingir de forma mais significativa e inovadora os objetivos estratégicos do MST. 
É evidente que, mesmo nos assentamentos individuais, os Sem Terra continuam de algum modo articulados, tanto pela proximidade das moradias, que possibilita a reunião em torno de causas específicas, quanto pela relação que a coordenação de cada brigada mantém com a direção nacional do movimento. Mas não estamos mais tratando de uma necessidade objetiva de união para a luta. A práxis cotidiana tende a ser individualista, familiar, de defesa da propriedade. Há uma tendência mais forte àquilo que lasi (2006), após Sartre, chama de retorno à serialidade. É em função disso, como afirma Vendramini (2003, p. 3), que “[...] uma das estratégias do MST na organização dos assentamentos é a formação de cooperativas, com o objetivo de viabilizá-los economicamente e manter a coesão do grupo e a sua capacidade de organização política”.

De acordo com a Concrab (1995, p. 8), a concepção de cooperação do MST objetiva, entre outras coisas, o desenvolvimento econômico-social e de valores humanistas e socialistas. "A cooperação que buscamos deve estar vinculada a um projeto estratégico, que vise a [sic] mudança da sociedade. Para isto [sic], deve organizar os trabalhadores, preparar e liberar quadros, ser massiva, de luta e de resistência ao capitalismo". Dessa forma, dentre diversos objetivos imediatos da cooperação no MST, o assentamento coletivo tem por finalidade o cultivo da política do movimento e "[...] do homem novo [...]", portador de valores socialistas. "A cooperação deve ser vista como um meio. O objetivo final são as transformações sociais e as melhorias permanentes das condições de vida" (CONCRAB, 1995, p. 9).

Parece-nos claro que a estratégia do MST, ao retomar a bandeira do cooperativismo, não é aquela que pretende superar o capitalismo substituindo-o via mercado, progressivamente, pela produção cooperativa. Suas cooperativas são meios, como outros, para a permanente educação política necessária a essa luta, que tende ao refluxo, quando se move do acampamento ao assentamento. Se a luta política deve continuar após a conquista da terra, seus militantes devem se organizar em uma forma que contribua sensivelmente para tanto. 


\section{CONSIDERAÇÕES FINAIS}

O cooperativismo possui estreita ligação com o sistema capitalista. Suas origens remontam à negação da crescente ascensão e domínio da propriedade privada dinâmica dos meios de produção. Como práxis de resistência dos trabalhadores, as cooperativas são capazes de negar parcialmente alguns dos efeitos desumanizantes do modo de produção capitalista - sobretudo os relacionados à divisão hierárquica do trabalho -, mas são ao mesmo tempo ontologicamente incapazes, por si mesmas, de superar o capitalismo.

Em tempos em que, especialmente no Brasil, a ilusão dos socialistas utópicos de transcender o modo de produção capitalista através do cooperativismo é reiventada pela Economia Solidária, o MST apresenta-o como instrumento político-organizativo substancialmente diferente e de modo significativamente inovador. A especificidade das cooperativas do MST encontra-se no processo educativo que desempenham as cooperativas deste movimento.

Após assentarem-se, os Sem Terra se deparam com diversos desafios relacionados à produção: é necessário trabalhar competitivamente para defender as terras conquistadas. Mas, também, com desafios de natureza política: é importante manter a coesão do grupo que permitiu superação das impossibilidades postas pela sociabilidade capitalista; é necessário manter aceso o sentimento de pertença ao grupo e seus inerentes laços de solidariedade que rompem com as cápsulas individualizantes construídas por nossa sociedade.

Esses elementos - a nosso ver, enfrentados com a correção de que são multiplamente determinados uns pelos outros - possibilitam mais que assegurar a coesão interna, mas formar os militantes ao mesmo tempo em que asseguram minimamente a organização interna e a formação técnica dos trabalhadores. Desse modo, criam meios para que possam empreender, com domínio técnico e razoável controle interno da produção, novas práticas de organização do trabalho, adequadas tanto à produção material dos valores de uso e de troca quanto à formação política destes mesmos militantes. As lutas do MST, portanto, não encerram sua causa na conquista dos meios de produção para sua própria 
sobrevivência, mas, ao contrário, identificam no fim da propriedade privada desses meios de produção o fator fundamental para a superação da sociedade capitalista.

O surgimento do homem novo a partir de novas relações sociais, que ocupou o pensamento de diversos revolucionários, entre os quais Ernesto Che Guevara, é germinado no MST, também nos assentamentos, em suas lutas como prática educativa. Seu livre desenvolvimento, contudo, só será possível com a transcendência positiva das relações sociais capitalistas em sua totalidade.

\section{REFERÊNCIAS}

CONCRAB. Perspectivas da cooperação agrícola nos assentamentos. Caderno de Cooperação Agrícola, São Paulo, n. 4, 1995.

DALMAGRO, Sandra Luciana. Trabalho, coletividade, conflitos e sonhos: a formação humana no assentamento Conquista na Fronteira. 2002. 169 f. Dissertação (Mestrado em Educação) - Programa de Pós-Graduação em Educação, Universidade Federal de Santa Catarina, Florianópolis, 2002.

FARIA, José Henrique de. Tecnologia e processo de trabalho. Curitiba: UFPR, 1992.

GERMER, Claus. O desenvolvimento do capitalismo no campo brasileiro e a Reforma Agrária. In: STÉDILE, J. P. A Questão agrária hoje. 2. ed. Porto Alegre: Edição da Universidade/UFRGS, 1994 a.

. Perspectivas das lutas sociais agrárias nos anos 90. In: STÉDILE, J. P. A questão agrária hoje. 2. ed. Porto Alegre: Edição da Universidade/UFRGS, 1994 b.

IASI, Mauro Luís. As metamorfoses da consciência de classe: o PT entre a negação e o consentimento. São Paulo: Expressão Popular, 2006.

LUKÁCS, George. As bases ontológicas do Pensamento e da Atividade do Homem. 1969. [Tradução de Carlos Nelson Coutinho]. Disponível em: <http://pt.scribd.com/doc/6973970/Georg-Lukacs-As-bases-ontologicas-do-pensamento-e-da-atividade-do-homem>. Acesso em: 18 jul. 2011. 
LUXEMBURGO, Rosa. Reforma ou revolução? São Paulo: Expressão Popular, 1999.

MACHADO, Eliel. A (des)constituição de classe no MST: dilemas da luta anti-sistêmica. Lutas Sociais, São Paulo, v. 17/18, p. 170-182, 2007.

MACHADO, Eliel; GONÇALVES, Renata. Da possível constituição de classe nos acampamentos ao refluxo político-ideológico nos assentamentos do MST. Lutas e Resistências, Londrina, n. 2, p. 10-19, $1^{\circ}$ sem. 2007.

MARX. Karl. O Capital: crítica da economia política: Livro Primeiro, Tomo I. 3. ed. São Paulo: Nova Cultural, 1988.

. O Capital: Crítica da Economia Política: Livro Primeiro, Tomo Il. 2. ed. São Paulo: Nova Cultural, 1985.

. O Capital: Crítica da Economia Política: Livro Terceiro, Tomo I. 2. ed. São Paulo: Nova Cultural, 1986.

MÉSZÁROS, I. O poder da ideologia. São Paulo: Boitempo, 2004.

. A crise estrutural do capital. São Paulo: Boitempo, 2009.

MORISSAWA, Mitsue. A história da luta pela terra e o MST. São Paulo: Expressão Popular, 2001.

TONET, I. O pluralismo metodológico: um falso caminho. Serviço Social e Sociedade, São Paulo, n. 48, 1995.

VENDRAMINI, Célia Regina. A Experiência Coletiva como Fonte de Aprendizagem nas Lutas do Movimento Sem Terra no Brasil. Revista Lusófona de Educação, Lisboa, n. 6, p. 67-80, 2005.

- Assentamentos do MST e Identidade Coletiva. In: REUNIÃO ANUAL DA ASSOCIAÇÃO NACIONAL DE PÓS-GRADUAÇÃO E PESQUISA EM EDUCAÇÃO, 26., 2003, Poços de Caldas - MG. Novo governo, novas políticas? O papel histórico da ANPEd na produção de políticas educacionais. Poços de Caldas: ANPEd, 2003. 